\title{
Diretrizes curriculares nacionais para o ensino médio: avaliação de documento ${ }^{1}$
}

\section{Resumo}

Este texto pretende oferecer algumas contribuições para o debate sobre as mudanças propostas pelas Diretrizes Curriculares Nacionais elaboradas para a reforma do ensino médio no Brasil. Na primeira parte, avalia-se o cenário político e econômico, como contexto gerador da última etapa de reformas no âmbito da educação, nos anos 90. Pretende-se questionar a opção por um modelo de reforma de estrutura (no caso brasileiro mais restrita ao Programa de Reforma da Educação Profissionalizante - PROEP) e de currículo, cujos temas encontram justificativa no contexto econômico, social, cultural e político contemporâneo. Discute-se a utilização de um "modelo" que toma por base experiências desenvolvidas em outros países, e por referência teórico-metodológica as orientações internacionais de organismos multilaterais, desconsiderando as peculiaridades e injunções do sistema administrativo-político brasileiro, medida política essa que pode aumentar a tensão e a distância normalmente existentes entre programas de governo e a possibilidade de sua concretude na rede escolar. Na segunda parte, discute-se a Resolução do Conselho Nacional de Educação, da Câmara de Educação Básica, n. 3, de 16.6.98, que institui as Diretrizes Curriculares Nacionais para o ensino médio, bem como as Bases Legais - Parte I - dos Parâmetros Curriculares Nacionais para o Ensino Médio. A análise do discurso oficial toma como referência metodológica a proposição de Bardin (1977, p. 209) para os modelos de análise estrutural, procurando-se relevar os valores implícitos e as conotações dos textos legais.

\section{Abstract}

This text offers some contributions to the debate on the changes proposed to the National Curricular Directives to reform secondary education in Brazil. In the first part, the political and economic scene is evaluated as the context which generated the last stage of reforms in the educational field in the $90 \mathrm{~s}$. It questions the option for a model of structural reform (in the Brazilian case more restricted to the Program for Reform of Professional Education - PROEP) and of the curriculum, whose themes find their justification in the contemporary economic, social cultural and political context. It discusses the use of a "modell" that bases itself on experiences developed in other countries and takes the international orientation of the multilateral organizations as its theoretical methodological reference, leaving out the peculiarities and injunctions of the Brazilian political administrative system. Such a policy measure can increase the tension and distance normally existing between government programs and the possibility of their real implementation in the school network. In the second part, it discusses the Resolution of the National Education Council, the Congress on Basic Education, no.3, of 16.698 that instituted the National Curricular Directives for secondary education, as well as the Legal Bases - Part I - of the National Curricular Parameters for secondary education. The analysis of official discourse takes Bardin's (1977, p. 209) proposals as its methodological reference for the models of structural analysis, seeking to make the implicit values and the connotations of the legal texts explicit.

*Doutora em Educação ( Administração e Supervisão Escolar). Mestre em Educação (Administração Escolar); bacharel em Ciências Sociais e Políticas. Professora das Faculdades Integradas "Campos Salles" e Pesquisadora da Fundação Carlos Chagas.

'Originalmente publicado nos "Cadernos de Pesquisa" da Fundação Carlos Chagas - n.104, abr. 2000. Publicação na Augusto Guzzo Revista Acadêmica autorizada pela autora. 


\section{Introdução}

Discutir aspectos legais de reformas operadas pelo Estado, sempre implica realizar uma análise parcial da dinâmica que se instaura em razão da legislação. Entre o discurso normativo do Estado e a prática efetiva dos atores responsáveis pela operacionalização das diretrizes preconizadas, há uma distância considerável.

No entanto, pretende-se, neste texto, apenas contribuir para o debate instaurado decorrente da força da lei, que impõe, queiramos ou não, mudanças na dinâmica de funcionamento das políticas setoriais. Toda mudança legislativa deflagra um processo que desacomoda os atores e o sistema em que atuam, promovendo discussões, questionamentos, mudanças na regulamentação das práticas, e, muitas vezes, provocando resistências por parte daqueles responsáveis pela sua implementação ${ }^{2}$. O produto híbrido gerado desse processo, invariavelmente, expressa um conjunto de modificações imprimidas pela dinâmica do cotidiano da rede de escolas em relação às diretrizes emanadas originalmente da lei.

Porém, apesar dos limites da análise realizada nesses moldes, pretende-se discutir algumas mudanças apontadas pela legislação na definição de temas curriculares. Parte-se do pressuposto que a análise da lei sempre deve levar em conta seus princípios políticos: quais são as finalidades implícitas na organização e seleção de conteúdos? Por que alguns temas aparecem e outros estão ausentes? Os princípios pedagógicos da interdisciplinaridade e da contextualização representam realmente uma possibilidade de ruptura no tratamento metodológico das disciplinas? Outras questões, ainda, merecem destaque, tais como a concepção de conhecimento vinculado ao seu uso instrumental - a tecnologia - e a maneira de apreendê-lo.

Segundo os Parâmetros Curriculares Nacionais para o Ensino Médio (Brasil, 1999), o Ministério da Educação - ao propor a reforma do ensino médio - procura atender às necessidades postas por um cenário de profundas mudanças sociais, econômicas, políticas e culturais de âmbito mundial.

De um lado, portanto, são as características desse cenário presentes nos contextos regionais que merecem uma discussão, pois criam demandas de reformas no âmbito das políticas setoriais, como conseqüência de mudanças na organização do mundo do trabalho, nos mecanismos de poder e nas funções do Estado. Sem a pretensão de realizar uma exaustiva análise da imbricação entre diretrizes e orientações provenientes de organismos multilaterais, e/ou referenciadas em reformas de ensino encetadas por outros países, e as Diretrizes Curriculares propostas para o ensino médio brasileiro - e sem acreditar, ainda, numa relação unilateral - creio que o cenário gerador dessas mudanças merece alguma discussão.

De outro lado, pretende-se avaliar os pressupostos filosóficos e sociais das Diretrizes e dos Parâmetros Curriculares Nacionais para o ensino médio, partindo-se do pressuposto que expressam uma determinada concepção de educação, de escola e de conhecimento que deve ser olhada criticamente.

\section{Avaliação de cenário: os condicionantes políticos e econômicos}

Relacionar o atual processo de globalização às reformas empreendidas por diferentes países nas políticas setoriais é tema do qual vêm se ocupando vários teóricos da área das ciências sociais e humanas e dispensa maiores considerações. Parece haver consenso quanto ao impacto promovido nas políticas sociais pelas profundas mudanças econômicas, políticas e culturais compreendidas no processo dinâmico da globalização, tanto no que diz respeito à análise acadêmica, quanto no que afeta ao discurso oficial (Ortiz, 1998; Brasil, 1999).

No entanto, é importante assinalar apenas que esse processo constitui hoje um fenômeno que desestabiliza as bases nas quais se estrutura o sistema estatal. $\bigcirc$ modelo de Estado nacional

\footnotetext{
${ }^{2}$ Sobre a prática de resistência de educadores diante de mudanças propostas em programas educacionais, ver: Martins, 1996.
} 
vigente, a partir do século XVI - demarcado territorialmente e cujas relações entre a política, a economia e as demandas da sociedade civil foram negociadas e configuradas no âmbito interno das nações - não responde mais às necessidades postas pela reorganização do mundo do trabalho e da dinâmica social dele decorrente.

No período histórico mais recente, a partir da segunda metade do século XX, consolida-se uma etapa em que o Estado se estrutura definitivamente como provedor das políticas de bem-estar social (Draibe, 1992). Esse padrão de intervenção, no entanto, passa a sofrer fortes críticas, a partir dos anos 80 , sobretudo, gerando uma crise no modelo de Estado centralizado, acompanhada de uma crise na concepção de suas funções e papéis: de solução para todos os problemas de desigualdade intrínsecos ao capitalismo, o Estado passa a ser o problema central dessa crise.

É importante salientar, porém, que o atual processo de redefinição de suas funções - ou a emergência do que alguns teóricos denominam de Estado restrito - não implica necessariamente na diminuição de seu poder. Segundo Ball:

“(...) a terceirização, a desregulamentação e a privatização têm reduzido, tanto em termos práticos quanto em termos ideológicos, a capacidade de intervenção estatal direta. Entretanto, isso não significa dizer que esses dispositivos de política não fornecem novas formas de controle estatal e regulação." (1999, p.4)

Senão vejamos. O Estado permanece como centro de organização do poder político burguês e não pode ser confundido com o poder político restrito que o administra: ele é amplo, no sentido em que é coñstituído "pelos mecanismos da produção da mais-valia, ou seja, por aqueles processos que asseguram aos capitalistas a reprodução da exploração" (Bernardo, 1991, p. 162). Nesse sentido, ao realizar sua função essencial - a de dominação de classe - cabe a esse Estado, ao mesmo tempo, administrar os interesses contraditórios dos diferentes segmentos que compõem as classes dominantes e entre estes e as classes dominadas.

Esse jogo tenso e contraditório - que impõe limites às suas funções e, concomitantemente, amplia seu poder de operacionalização, para implementação de regras de amplitude internacional - coloca em cheque, particularmente, os valores universais que até então deram sustentação às democracias ocidentais burguesas. No presente momento,

"(...) o atual processo de transnacionalização do capitalismo tem contribuído para evidenciar, mais uma vez, que a função precípua do capital, seja em formações sociais marcadas pela ética protestante, católica, contra-reformista, confuciana ou xintoísta, é acumular capital e fazer com que a estrutura de sua reprodução seja garantida por reformas na configuração do Estado."

$$
\text { (Almeida, 1998, p. 183) }
$$

Na atual fase, a soberania das nações está submetida às forças que operam internamente promovendo demandas na sociedade civil, enquanto o Estado opera, cada vez mais, obedecendo às demandas externas. Nesse jogo contraditório, a reforma nas suas estruturas e aparato de funcionamento têm sido inevitáveis: "a desregulamentação da economia, a privatização das empresas produtivas estatais, a abertura de mercados, a reforma dos sistemas de previdência social, saúde e educação, dentre outros, são apenas alguns dos seus aspectos de mudança" (Ianni, 1998, p. 20).

Os organismos multilaterais de ajuda internacional que em alguns momentos apareceram como interventores nas políticas sociais nos países periféricos durante as décadas de 1960/70 definindo diretamente as reformas de ensino e financiando a estrutura que daria suporte às políticas públicas - ressurgiram, a partir dos anos 80 - como negociadores de questões sociais graves, promovidas por desmandos nas economias locais e no gerenciamento dos programas sociais, exercendo a função de principais interlocutores dos governos de países periféricos. 
Nesse sentido, o Banco Internacional de Reconstrução e Desenvolvimento - BIRD - o Fundo Monetário Internacional - FMI - o Convênio Geral de Tarifas e Comércio - GATT o Banco Interamericano de Desenvolvimento BID - a Associação Latino-americana para o Desenvolvimento Industrial e Social - ALADIS e a Comissão Econômica para a América Latina CEPAL - são alguns desses órgãos que se têm mobilizado para colocar as diretrizes sociais e econômicas em patamares de governabilidade (Ianni, 1995), financiando apenas alguma expansão e/ou avaliação de políticas públicas setoriais já estruturadas.

Os anos 80 também vêem surgir os movimentos étnicos, de raça, de gênero, da diferença, de problemas de povos colonizados, de minorias reprimidas e de questões ecológicas e estéticas, que conquistam o cenário internacional e o estatuto teórico de categorias analíticas, investigando problemas até então desprezados ou ignorados pelas teorias marxistas ortodoxas. Legitimam-se como movimentos capazes de mobilizar segmentos sociais expressivos, diante do fracasso do modelo de fazer política encetado por partidos de esquerda e pela democracia burguesa clássica.

É inegável a importância da emergência dos graves problemas étnicos, raciais, de gênero, ecológicos, de religião e dos movimentos sexistas, organizados em movimentos sociais vigorosos que passam a substituir os clássicos movimentos operários. Esses novos temas aparecem como eixos centrais nas reformas de currículo contemporâneas ${ }^{3}$, encetadas por muitos países e devem também ser compreendidos no âmbito da lógica global das recentes mudanças da economia, da política e da cultura.

Também os anos 70 representam um marco histórico na dinâmica de mudanças provocadas por profundas transformações: na economia, com o início de um processo de transição do modelo fordista-taylorista para o modelo de acumulação flexível; na política, com a transição do Estado centralizador e regulamentador para instâncias descentralizadas e a instauração de medidas de desregulamentação da economia e de normas legislativas; na cultura, com a transição do modernismo - da ética - para o pós-modernismo - da estética -, dando novas configurações à cultura e à vida social (Harvey, 1995).

Esse processo de mudanças - cujo início tem sido invariavelmente relacionado aos anos 70 por muitos teóricos - consolida-se nos anos 90 , apresentando setores de produção inteiramente novos; novas maneiras de fornecimento de serviços financeiros; novos mercados; mudanças no padrão de desenvolvimento desigual (tanto entre setores da economia quanto entre regiões geográficas); compressão do espaço e do tempo; níveis altos de desemprego estrutural; rápida destruição e reconstrução de habilidades; ganhos modestos e retrocesso do poder sindical (Harvey, 1995, p. 148).

O peso das informações e seu controle aliado à análise dos dados têm permitido às organizações um nível de coesão antes impossível: o conhecimento passa a ser visto como a principal mercadoria e a ser organizado em bases cada vez mais competitivas (Harvey, 1995, p. 151). Constitui, dessa forma, o suporte fundamental para um processo de produção cada vez mais baseado em economia de escopo e não mais de escala, cujas principais características em relação ao trabalho podem assim ser resumidas: múltiplas tarefas e eliminação de sua demarcação; pagamento pessoal (há um sistema detalhado de bonificações); longo treinamento; organização horizontal do trabalho; ênfase na co-responsabilidade do trabalhador (Harvey, 1995, p. 149).

Assim, a flexibilidade na organização do trabalho; a exigência de trabalhadores polivalentes, cooperativos e capazes de desenvolver toda sua potencialidade de aprendizagem e de trabalho; a emergência da "política da diferença"; a eleição do conhecimento como mola propulsora desta última etapa de desenvolvimento do capitalismo, constituem o caldo cultural que tem permeado as mudanças operadas no conceito da educação necessária para formação da mão-de-obra:

${ }^{3}$ Ver, particularmente, os seguintes documentos: Argentina (1994); Chile (1991); Espanha (1992). 
"Os novos modelos de produção industrial, sua dependência das mudanças de ritmo nas modas e necessidades preferidas pelos consumidores e consumidoras, as estratégias de competitividade e de melhora da qualidade nas empresas, exigem das instituições escolares compromissos para formar pessoas com conhecimentos, destrezas, procedimentos e valores de acordo com esta nova filosofia econômica." (Torres Santomé, 1998, p. 20).

Gradativamente, nas reformas dos sistemas de ensino aparecem conceitos e propostas tais como descentralização; autonomia dos centros escolares; flexibilidade dos programas escolares; liberdade de escolha de instituições docentes; necessidade de formação continuada; superação do conhecimento fragmentado; importância da participação do recurso humano - em contraposição à relevância dos recursos tecnológicos como apregoava o pensamento fordista - na resolução dos problemas da empresa. Esses conceitos encontram correspondência nas características da reorganização do mundo produtivo: na descentralização das grandes corporações industriais; na autonomia relativa de cada fábrica em decorrência do processo de desterritorialização das unidades de produção e/ou de montagem; na flexibilidade da organização produtiva, para ajustar-se à variabilidade de mercados e de consumidores (Torres Santomé, 1998, p. 21).

Invariavelmente, as orientações que vigoram internacionalmente - sejam elaboradas por organismos multilaterais, sejam aquelas adotadas nos programas de reformas da educação de determinados países - retomam a discussão realizada pelas diretrizes tecnicistas internacionais dos anos 70 sobre o ajuste necessário que os sistemas de ensino devem sofrer para atender às novas demandas do mundo do trabalho, estabelecendo uma relação linear e, por isso mesmo perigosa, entre essas mudanças - muitas vezes, equivocadamente, compreendidas como rupturas de paradigmas no âmbito econômico, social e cultural - e as políticas de formação de recursos humanos aptos a enfrentá-las ${ }^{4}$.
No Relatório sobre o Desenvolvimento Mundial (BIRD, 1995), o Banco Mundial, ao discutir as estratégias de desenvolvimento que favorecem o trabalhador, examina a relação entre o desenvolvimento a longo prazo e o futuro reservado ao trabalhador, as conseqüências do crescimento econômico, a natureza das interações das famílias com os mercados de trabalho, as opções de política que afetam o crescimento da mão-deobra e a provisão de aptidões. Finalmente, discute como os resultados de mercado afetam as desigualdades e como são distribuídas as recompensas de crescimento.

Ao discutir especificamente as aptidões para o desenvolvimento, o documento retoma a concepção de capital humano, afirmando que:

“... a educação é essencial para o aumento da produtividade individual. A educação geral dota a criança de habilidades que podem ser mais tarde transferidas de um trabalho para outro, e dos instrumentos intelectuais básicos, necessários para a continuação do aprendizado. A educação aumenta a capacidade de desempenhar tarefas normais, de processar e utilizar informações e de adaptar-se a novas tecnologias e práticas de produção.” (BIRD, 1995, p. 42)

A perda da eficácia e eficiência dos sistemas de ensino tem sido discutida em grande parte das pesquisas acadêmicas e apontada em extensos relatórios elaborados para os organismos internacionais (Carnoy e Castro, 1996). Nos países desenvolvidos, esses estudos têm demonstrado que a população jovem apresenta novas formas de analfabetismo (funcional), ausência de compreensão dos códigos básicos de habilidades e, conseqüentemente, uma notável falta de preparação para ingressar no mundo do trabalho. Acrescentese a esses problemas apontados a inversão dos sistemas de ensino que começam a reproduzir e aumentar as desigualdades sociais e econômicas (Ottone, 1996; Carnoy, Castro, 1996).

Segundo Ottone (1996), a estrutura vigente nos sistemas de ensino reflete o modelo das sociedades industriais transposto para os países

${ }^{4}$ Ver, adiante, como essa relação linear é estabelecida nos Parâmetros Curriculares Nacionais para o Ensino Médio. 
em desenvolvimento, cuja concepção está mais ligada ao crepúsculo do século XIX do que ao nascimento do século XXI. Dessa forma, as mudanças em curso apontam para a necessidade de reforma na estrutura, na organização e na gestão dos sistemas de ensino; nos mecanismos de poder que ampliam ou diminuem a autonomia regional e local; nas políticas de currículo e na formação dos responsáveis pela sua implementação, os professores.

Particularmente em relação ao ensino médio, o aluno formado deverá estar apto para exercer as funções do futuro que são: capacidade de abstração; desenvolvimento de pensamento sistêmico complexo e inter-relacionado; habilidade de experimentação e capacidade de colaboração; trabalho em equipe; interação com os pares (UNESCO, 1994).

Invariavelmente, os documentos orientadores internacionais não fazem, porém, referências às graves questões que afetam a dinâmica da vida em sociedade: a discussão sobre a gravidade dos índices que acusam a ausência de emprego, por exemplo, é substituída pela visão otimista de que a escola preparará, competentemente, o jovem para o mercado de trabalho. De modo geral, as injustiças sociais, a distribuição desigual da riqueza e dos bens econômicos, a desigualdade nas possibilidades de acesso a um mercado de trabalho cada vez mais restrito passam ao largo das preocupações da literatura oficial da área ${ }^{5}$.

A educação formal e seus principais protagonistas - os professores - encontram-se hoje no centro da discussão acerca da importância que a escolaridade adquire perante os atributos requisitados pela globalização da economia, da política e da cultura. A ênfase nos quatro pilares que, segundo esta ótica, impulsionariam os países de economia periférica rumo à conquista da competitividade internacional, pode ser resumida na seguinte pauta: prioridade de investimentos na educação básica, de um lado, e na tecnologia, de outro; políticas definidas de formação inicial e continuada dos docentes; políticas integradas de formação profissional e qualificação da mão-de- obra (Carnoy, Castro, 1996).

Nesse contexto, ainda, as complexas questões que hoje afetam a dinâmica das sociedades têm sido reduzidas a algumas fórmulas eficientes na educação formal e que preconizam, dentre outros temas candentes e contemporâneos para as reformas de ensino, a adoção de eixos centrais que se denominam "códigos culturais da modernidade, isto é, a formação da cidadania e a preparação para o mercado de trabalho" (Garretón, 1997, p. 129).

\section{Sobre as diretrizes curriculares: algumas considerações}

Diante de tais mudanças, o ensino médio é aquele que tem acumulado maior defasagem em relação às suas origens históricas e capacidade de atendimento às demandas da sociedade; pensado na vertente científico-humanista como uma fase de transição ao ensino superior e, na vertente técnica como formação profissional voltada para iniciar os jovens no exercício de uma profissão, encontra-se defasado e questionado em ambas as versões. Se de um lado, o ensino médio forma jovens que têm acesso ao ensino superior, de outro, há um grande contingente de jovens e adultos inseridos no mercado de trabalho, que buscam acesso a novos conhecimentos que lhes permitam ascender econômica e socialmente.

A expansão das matrículas nesse nível de ensino é expressiva: entre 1985 e 1997 mais do que dobraram, concentrando-se nas redes estaduais e no período noturno (Zibas, Franco, 1999). Entretanto, segundo o próprio Ministério da Educação, o índice de escolarização líquida nesse nível de ensino, considerada a população de 15 a 17 anos, não ultrapassa 25\%, o que coloca o Brasil em situação de desigualdade em relação a muitos países, inclusive aos da América Latina (Brasil, 1999).

A reforma do ensino médio surge, no Brasil, portanto, como um dos itens prioritários da política educacional do governo federal, justificada pela necessidade de se adequar esse nível de ${ }^{5}$ Ver, por exemplo: Espanha (1991); Organización de Estados Iberoamericanos para la Educación, la Ciencia y la Cultura (1997 e 1998). 
ensino às mudanças postas "pela ruptura tecnológica característica da chamada terceira revolução técnico-industrial, na qual os avanços da microeletrônica têm um papel preponderante" (Brasil,1999, p.7), bem como pelas novas dinâmicas sociais e culturais constituídas no bojo desse processo de mudanças.

Para realizar a reforma proposta, o Ministério de Educação e do Desporto, partindo de princípios definidos pela Lei de Diretrizes e Bases da Educação Nacional n. 9.394/96 e compreendendo que o Brasil deve estar integrado à tendência internacional que tem implementado reformas nos sistemas de ensino para atender às exigências das mudanças econômicas, sociais e culturais em curso, empreende o Programa de Reforma do Ensino Profissionalizante (Decreto n. 2.208/97), institui as Diretrizes Curriculares Nacionais para o Ensino Médio (Resolução CEB, n. 3/98) e elabora os Parâmetros Curriculares Nacionais para o Ensino Médio (Brasil, 1999).

Em 17 de abril de 1997, o Decreto n. 2.208 regulamenta a educação profissional em

"articulação com o ensino regular ou em modalidades que contemplem estratégias de educação continuada, podendo ser realizada em escolas do ensino regular, em instituições especializadas ou nos ambientes de trabalho, compreendendo os seguintes níveis: básico, destinado à qualificação, requalificação e reprofissionalização de trabalhadores, independente de escolaridade prévia; técnico, destinado a proporcionar habilitação profissional a alunos matriculados ou egressos do ensino médio (...); tecnológico, correspondente a cursos de nível superior na área tecnológica, destinados a egressos do ensino médio e técnico."

Posteriormente, o Conselho Nacional de Educação - baseado no Parecer CEB n. 15/98 aprova a Resolução CEB n.3 de 26/6/98, instituindo as Diretrizes Curriculares Nacionais para o ensino médio. Em fins de 1999, o Ministério divulga, ainda, os Parâmetros Curriculares Nacionais para o Ensino Médio, versão mais elaborada de conceitos e princípios políticos e pedagógicos que aparecem anteriormente em documentos preliminares do Ministério, no Parecer CEB n. 15/98 e na própria Resolução CEB n. 3/98.

É interessante observar que, com esta última medida, a União não apenas estabelece a prescrição de um currículo nacional para o ensino médio - medida coerente, se considerarmos a dimensão continental do país e a necessidade daí decorrente de uma política democrática de acesso ao conhecimento sistematizado - mas acaba tomando para si uma tarefa que historicamente vem sendo assumida no âmbito estadual. A definição de parâmetros curriculares detalhados (Brasil, 1998b, 1998c, 1998d; Brasil, 1997b) denota forte intervenção federal na implementação do currículo, função essa desempenhada pelas Secretarias Municipais e Estaduais de Educação, sobretudo a partir da redemocratização do país nos anos 80 .

A Resolução CEB n. 3/98, em seu artigo 3으, sublinha que a organização do currículo, das situações de ensino-aprendizagem e dos procedimentos de avaliação devem estar coerentes com os princípios estéticos, políticos e éticos, abrangendo a estética da sensibilidade, a política da igualdade e a ética da identidade. Prossegue, no artigo 4ํㅡㄹ indicando que o currículo deverá incluir competências básicas, conteúdos e formas de tratamento dos conteúdos, organizando-se nos princípios pedagógicos da identidade, da diversidade, da autonomia, da interdisciplinaridade e da contextualização.

O tema da interdisciplinaridade merece alguma discussão, pois não constitui exatamente uma novidade (basta ler a Lei n. 5.692/71 e a legislação posterior que a regulamenta). Sobre essa noção, presente em muitas propostas curriculares elaboradas a partir dos anos 80 e sobre os equívocos cometidos em seu nome, muito já se discutiu também (Veiga-Neto, 1995). No entanto, é interessante salientar que, em seu artigo 8으, a Resolução n. 03/98 indica uma concepção de multidisciplinaridade muito mais próxima dos 
educadores e mais distante de sua definição científica: não se aponta uma integração entre as disciplinas, objetivando criar novos conhecimentos, mas sim, o texto explicita apenas a possibilidade de se instaurar um diálogo entre as diferentes disciplinas, para trocas de experiências e metodologias. Creio que novamente, o que a Resolução n. 3/98 pretende por interdisciplinaridade, compreende muito mais uma atitude metodológica em relação às disciplinas do currículo, do que propriamente propor uma discussão epistemoló- gica acerca de rupturas de fronteiras e fusão de estatutos teóricos entre as diferentes ciências, visando a produção de novos conhecimentos.

Com respaldo no artigo 26 da $\mathrm{LDB}$, o qual preceitua que os currículos do ensino fundamental e médio devem "ter uma base nacional comum, a ser complementada, em cada sistema de ensino e estabelecimento escolar, por uma parte diversificada, exigida pelas características regionais e locais da sociedade, da cultura, da economia e da clientela", a Resolução 3/98 (Art. 11) indica que a base nacional comum terá 2.400 horas (75\%), acrescidas da parte diversificada (25\%), e deverá se organizar nas seguintes áreas do conhecimento: Linguagens, Códigos e suas Tecnologias; Ciências Humanas e suas Tecnologias; Ciências da Natureza, Matemática e suas Tecnologias. Esclarece, ainda, que "as propostas pedagógicas das escolas deverão assegurar tratamento interdisciplinar e contextualizado para Educação Física e Arte, como componentes curriculares obrigatórios e conhecimentos de Filosofia e Sociologia necessários ao exercício da cidadania" (artigo 10, III - alínea $2^{\text {a}}$ ).

Em seu artigo 12, afirma que não haverá dissociação entre a formação geral e a preparação básica para o trabalho, nem esta última se confundirá com a formação profissional, pois será implementada acrescentando-se mais 2.400 à base nacional comum, sendo que "os estudos concluídos no ensino médio poderão ser aproveitados para obtenção de uma habilitação profissional, em cursos realizados concomitante ou seqüencialmente, até o limite de 25\% do tempo mínimo legalmente estabelecido como carga horária para o ensino médio" (artigo 13).

Algum debate já se estabeleceu em razão do Decreto n. 2.208/97 e da Resolução CEB n. 3/98. No entanto, é sempre interessante sublinhar a preocupação de boa parte dos teóricos que já analisaram as mudanças propostas, sobretudo no que tange à efetiva possibilidade de democratização desse nível de ensino ${ }^{6}$. Senão vejamos.

Parcelas pouco significativas da população jovem poderiam esperar oito anos para adquirir, primeiramente, a formação geral (incluindo-se a preparação básica para o trabalho) e, em seguida, concluir os estudos técnicos, ou teriam condições econômicas e sociais de fazê-lo concomitantemente. Quanto à efetiva democratização dos estudos profissionalizantes básicos qualificação, requalificação e reprofissionalização - teoricamente, esta última possibilidade de acesso à qualificação parece mais coerente em relação à política antes praticada, porém, ainda faltam estudos empíricos que demonstrem tanto os avanços apontados na legislação, quanto o sucesso dessas medidas para alocação de trabalhadores num mercado de trabalho em retração. É também preciso considerar que ainda falta clareza política na implementação do Plano Nacional de Educação Profissional - PLANFOR - uma vez que os recursos do Fundo de Assistência ao Trabalhador - FAT - utilizados pelo Ministério do Trabalho e Emprego, vêm sendo disputados pelas mais diferentes organizações públicas e privadas. Dessa forma, o deslocamento provocado por essa mudança nas diretrizes da formação profissional básica de jovens e adultos com risco de desemprego ou desempregados - deslocandose do Ministério da Educação para o Ministério do Trabalho - corre o risco de reduzir o que deveria ser uma política integrada de formação profissional a projetos e atividades pontuais, consolidando-se a perspectiva de uma política compensatória na área.

Outra questão a ser considerada e insistentemente apontada na Resolução n. $3 / 98$ e nos

${ }^{6}$ Ver, por exemplo, o número especial editado pelo Sindicato dos Professores do Ensino Oficial do Estado de São Paulo, sobre a reforma do ensino médio (APEOESP, 1999), e, também, Ferretti (1997). 
Parâmetros Curriculares Nacionais diz respeito à superação da situação provocada pela Lei n. $5.692 / 71$. Segundo estes documentos, nos anos 60 e 70, a política vigente priorizou a formação de especialistas capazes de dominar a utilização de maquinarias ou de dirigir processos de produção, propondo, para tanto, a profissionalização compulsória. Contemporaneamente, os desafios são de outra ordem, pois o volume de informações produzido em decorrência de novas tecnologias tem sido constantemente superado, exigindo novos padrões de formação: a meta principal, portanto, deve ser a formação geral, em oposição à formação específica, tendo em vista a volatilidade das informações e a permanente superação de paradigmas.

É de se perguntar: será que a dicotomia será realmente superada? Do contrário, vejamos: a Lei n. 9.394/96 procura conferir "identidade ao ensino médio, uma vez que está embasada em uma proposta de organização curricular que se articula em função de um núcleo comum e em torno de áreas do conhecimento a serem desenvolvidas com todos os que ingressarem neste nível de ensino". Ao mesmo tempo, o Decreto n. 2.208/97 propõe uma organização curricular própria e independente do ensino médio, com possibilidade de se cursar concomitante ou seqüencialmente.

Acrescente-se outra questão: a tensão existente hoje entre formação escolar e o complexo mundo do trabalho sofrerá distensão apenas como conseqüência de uma provável organicidade instituída por legislação, em que a pouco esclarecida preparação básica para o trabalho pode acabar ocupando, na parte diversificada do currículo, o espaço de disciplinas que permitam, além de discutir e questionar as relações sociais de produção, a desejada formação integral do aluno? Tudo indica que a escola, ao efetuar a releitura sobre a legislação e diante das imensas dificuldades de toda ordem - operacionais, ausência de recursos humanos com a formação adequada exigida, intervenientes burocráticos etc. - realize, mais uma vez, a "opção possível para educar os alunos para o trabalho", colocando no currículo disciplinas que, aparentemente, preenchem os requisitos imediatos de mercado.

O próprio mundo do trabalho, tendo em vista a ausência de empregos, é um forte condicionante da realidade das escolas que, ao terem que "optar" por disciplinas que comporão a parte diversificada do currículo - entre disciplinas "formadoras e reflexivas" e aquelas que aparentemente possam atender de imediato as necessidades de alocação de jovens e adultos no mundo do trabalho - escolherão estas últimas.

Além do mais, já se discutiu exaustivamente a ausência de formação inicial adequada dos professores, como um dos fatores mais dificultadores de mudança nas posturas sacralizadas de ensino, o que facilita à rede de escolas optar pelo "que está mais à mão", para que não se agrave ainda mais o quadro de problemas cotidianos que a afetam.

Os Parâmetros Curriculares Nacionais para o Ensino Médio ratificam, em sua primeira parte denominada Bases Legais, a concepção encontrada de forma menos elaborada nos documentos preliminares do Ministério e na Resolução n. 3/98, de que a educação constitui um processo intrinsecamente relacionado ao mundo produtivo e de que o conhecimento conquista, definitivamente, uma instrumentalidade conferida pelos novos paradigmas econômicos, sociais e culturais.

Segundo os "Parâmetros", no período imediatamente anterior (anos 60 e 70) defendia-se que a educação deveria ser um instrumento de conformação do futuro profissional ao mundo do trabalho, a partir da disciplina, da obediência, do respeito às regras estabelecidas para a conquista da inclusão social, via profissionalização. Atualmente, porém, a revolução tecnológica e seus desdobramentos na produção e na informação asseguram à educação uma autonomia antes impossível, na medida em que o desenvolvimento das competências cognitivas e culturais exigidas para o pleno desenvolvimento humano passa a coincidir com o que se espera na esfera da produção:

"o novo paradigma emana da compreensão de que, cada vez mais, as competências desejáveis ao 
pleno desenvolvimento humano aproximam-se das necessárias à inserção no processo produtivo (...). $\mathrm{Ou}$ seja, admitindo tal correspondência entre as competências exigidas para o exercício da cidadania e para as atividades produtivas, recoloca-se o papel da educação como elemento de desenvolvimento social." (Brasil, 1999, p. 13).

A centralidade, que o conhecimento e a educação adquiriram nos processos de reorganização da produção e das dinâmicas sociais, tem-se refletido nos debates acadêmicos, nos documentos de organismos multilaterais e nas reformas do ensino ora em curso (Miranda, 1997; Martins, 1999).

É interessante observar, portanto, a concepção de conhecimento expressa nesses documentos oficiais, para se perguntar em que medida as teorias psicopedagógicas utilizadas e a inflexão excessivamente psicologizante contida, por exemplo, nos Parâmetros Curriculares Nacionais para o ensino fundamental, correspondem à matriz de conhecimento efetivamente necessário para responder às demandas do processo de mudanças sociais, econômicas, históricas, políticas e culturais aceleradas pela transnacionalização do capital? Acrescente-se, ainda, outra questão: a denominada sociedade do conhecimento, na realidade uma redefinição do conceito de capital humano (Frigotto, 1999), teria suas demandas prioritárias - criação de conhecimentos novos, informação e difusão preenchidas pelas políticas públicas educacionais, independentemente da desigualdade econômica e social dos diferentes países que adotaram as orientações dos organismos internacionais? Isto é, o conhecimento - como mola propulsora desta última etapa de reorganização do mundo produtivo e da vida social - seria a panacéia para todos os países envolvidos em reformas dos sistemas de ensino, independentemente de suas formações históricas, econômicas, sociais e culturais, características estas que condicionam inserções diferentes no mercado internacional e possibilidades totalmente diversas de apropriação coletiva do conhecimento produzido socialmente pela humanidade?

Dessa forma, a complexa questão de se erigir o conhecimento, como, supostamente, o eixo central dessas reformas educativas, exigiria um aprofundamento acerca não apenas do significado dessa eleição, mas dos significantes que permitiriam o desvelamento de sua concepção. Nesse sentido, compartilho com Popkewitz (1997, p. 13), a noção de que o conhecimento em sua relação com o poder nos permite expressar "nossos desejos pessoais, nossas vontades, nossas necessidades físicas e nossos interesses cognitivos". Nessa perspectiva, todo texto - ou toda prática discursiva - é uma prática social que predomina em determinado período histórico. Interessa, portanto, compreender as relações que a engendram e não apenas o discurso em si.

Visto de outra perspectiva ideológica - pois é disso que se trata - o conhecimento tecnológico, a ciência aplicada ou a ciência instrumental como quer que se queira denominá-lo - funciona com base na transferência de tecnologia entre o Norte e o Sul e expressa a introdução de inovações, a partir do deslocamento de um equilíbrio de poderes entre as nações. Segundo Calame (1995, p. 433-34), para os países produtores de tecnologia, o "meio de acolhida", isto é, os países receptores, são considerados apenas "bacias de competências" que detêm disponibilidade de atividades profissionais complementares, organizadas por um know-how que, necessariamente, não precisa estar formalizado ou mobilizado em universidades, centros de pesquisa, empresas e corporações. Invariavelmente, esse know-how derivado pode-se organizar pontualmente - através de parcerias, convênios etc. - e atendendo apenas às necessidades de escoamento das tecnologias recebidas.

A mediação entre países produtores e receptores de tecnologia, dessa forma, é realizada em dois sentidos: numa linha descendente considerada secundária e, em outra, ascendente que é a mais complexa. Na primeira, aparentemente, há uma oferta científica que satisfaz as demandas sociais. $\mathrm{Na}$ segunda, há um desejo coletivo e 
social difuso a ser traduzido em produto vendável. Neste último caso, genericamente, há um problema que aparece no âmbito da sociedade de forma difusa, iniciando um processo de mobilização em busca de sua resolução. Essa busca é o elemento que mobiliza a rede de competências necessárias, a partir de uma dimensão intercultural. Formam-se "passarelas diferentes de conhecimento" no mundo da produção: pesquisa/desenvolvimento, marketing/vendas, até que o produto conquiste o mercado.

O modelo mental de transferência de tecnologia tem, ainda, outro registro: dos que sabem aos que não sabem, mas querem e precisam ter seus desejos coletivos alimentados. A mediação entre as linhas ascendente e descendente se dá pela quebra de resistências ao progresso, à razão, à ciência pragmática e ao produto ofertado. No entanto, essa mediação aparece como mera tentativa de detecção ou busca de solução para problemas difusos gerados na sociedade.

Desse modo, o campo de passarelas, que constituirá o conhecimento necessário à satisfação dessas demandas nos países receptores, tende a permanecer na dependência da lógica desse modelo, ou seja, restrito à rede solvente dos produtos, de um lado e, de outro, ela pode ser considerada o resultado da mobilização de um knowhow regional e, portanto, geradora de novos conhecimentos. No entanto, os pilares de sustentação do campo de passarelas desses conhecimentos derivados seguirão o modelo mental de transferência de tecnologias: dos que sabem para os que não sabem.

Nesse sentido, a ampliação da escolaridade (Calame, 1995, p.433) constitui apenas um dos aspectos destinados a alimentar a rede solvente do complexo tecnológico: quanto mais o knowhow regional estiver mobilizado formalmente, ou seja, estiver organizado na rede formal de educação (incluindo-se os centros de pesquisa) e/ou em parcerias com as organizações produtivas no país receptor, a transferência de tecnologia será mais bem sucedida.

Dessa forma, uma determinada concepção de conhecimento, que aparece como "política geral da verdade" (Foucault, 1977), tem fundamentado as reformas dos sistemas de ensino em âmbito internacional e constitui o eixo central dos Parâmetros Curriculares Nacionais para o Ensino Médio, desconsiderando a complexidade que reveste tanto o conceito quanto sua produção.

Da maneira como vem sendo apresentada, essa concepção de conhecimento deve ser analisada e compreendida como um dos elementos fundamentais para potencializar as exigências da racionalidade instrumental dos processos produtivos (Frigotto, 1999), visando obter resultados imediatos e precisos nos termos enunciados pela pedagogia das competências (Ropé, Tanguy, 1998).

Os Parâmetros Curriculares Nacionais para o Ensino Médio sublinham, ainda, que a reforma curricular apresentada está pautada nas diretrizes gerais e orientadoras apontadas pela UNESCO (1994): aprender a conhecer; aprender a fazer; aprender a viver e aprender a ser. Modelos operacionais indicados ou utilizados em sistemas de ensino para melhorar o processo ensino-aprendizagem não são também uma novidade (a Lei n. 5.692/71 novamente pode ser citada como uma releitura obrigatória). Em princípio, o que parece diferente, no presente momento, é a tentativa de sua utilização, aproximandoo de uma concepção de conhecimento menos instrumental, mais flexível e, conseqüentemente, mais próximo dos paradigmas propostos pela ciência contemporânea, ${ }^{7}$ e pelas tendências recentes e progressistas que têm fundamentado o pensamento pedagógico.

Azanha (1996), ao criticar a prevalência de uma concepção psicologizante nas diretrizes cur-

\footnotetext{
${ }^{7 " A o}$ longo do século XX, a física foi a ciência que influenciou significativamente a mudança de paradigmas no mundo da produção científica, a partir da consolidação da mecânica quântica. Categorias tais como imprevisibilidade, flexibilidade e imponderabilidade passaram a compor o estatuto de uma ciência que não preconiza verdades, que apenas indica tendências" (Kaufmann, 1977).
} 
riculares nacionais para o ensino fundamental no $\mathrm{Brasil}^{8}$, seguindo a tendência sobretudo do currículo implementado pelo Governo da Espanha, fundamentado nas teorias piagetianas, afirma que:

“...mesmo que não se coloque em dúvida a questão da prioridade da Psicologia ou da Psicopedagogia, ainda haveria a questão da preferência por uma particular teoria. É compreensivel que as opções teóricas sejam assumidas de maneira persistente por cientistas individuais, mas a própria ciência como um empreendimento cultural coletivo necessita das divergências e das visões antagônicas, isto é, do pluralismo teórico." (p.6)

O que a Resolução n. 3/98 propõe, ainda, como um dos principais eixos norteadores - trabalhar as diferentes ciências relacionando-as ao seu uso tecnológico - também não constitui exatamente novidade, no que diz respeito à apresentação de uma proposta curricular de acordo com as necessidades contemporâneas dadas pelo mundo do trabalho (e nem deveria estar resumida a isso...).

A preocupação de questionar, discutir e compreender o complexo mundo da ciência pura e relacioná-lo à ciência aplicada, pode ser encontrada em diversas propostas curriculares. Durante os anos 80 , as secretarias estaduais de educação e algumas secretarias municipais realizaram ampla reforma das propostas curriculares. Essas reformas introduziram uma discussão metodológica acerca dos conteúdos desenvolvidos nas diferentes disciplinas nas escolas de ensino fundamental e médio, propondo uma aproximação maior entre os problemas e temas pesquisados nos centros de produção do conhecimento e seu uso didático, propiciando uma formação mais adequada e próxima da realidade vivenciada pelo aluno.

Dessa forma, algumas propostas curriculares introduziram como eixo norteador a discussão sobre o processo de construção dos conceitos científicos e a complexidade de sua tradução em produtos tecnológicos ${ }^{9}$, para que o aluno, mais do que compreender a dinâmica de produção de bens - cada vez mais suportado em tecnologias de ponta -, pudesse questionar o atual estágio de desenvolvimento das sociedades cujas relações mercantis têm estruturado patamares insuportáveis de desigualdade econômica e social. $\mathrm{O}$ que parece diferente agora?

O texto da Resolução parece indicar uma relação unilateral entre a concepção de instrumentalidade da ciência e a possibilidade de preparação básica para o trabalho, o que denota um equívoco. Não há mecanismo institucional que garanta que os princípios pedagógicos norteadores dessas diretrizes, por mais corretos que possam parecer de per si, contemplem essa preparação.

Ressalte-se, ainda, que a Resolução propõe uma visão "metodológica renovada para o ensino médio”, repousando sua concepção de mundo na seguinte afirmação:

"A organização do currículo deve ser coerente com princípios estéticos, políticos e éticos, abrangendo "a estética da sensibilidade, que deverá substituir a da repetição e padronização, estimulando a criatividade, o espírito inventivo, a curiosidade pelo inusitado, e a afetividade, bem como facilitar a constituição de identidades capazes de suportar a

\footnotetext{
${ }^{8}$ Ver, também, a observação realizada por Cunha ao avaliar os Parâmetros Curriculares Nacionais para o Ensino Fundamental (Convívio e Ética) sobre a prevalência de objetivos atitudinais (que o autor denomina ideológicos, no seu sentido mais amplo, pois são provisórios) em relação aos objetivos específicos de ensino dos conteúdos: "Na prática, é possível que cada área curricular, especialmente as fortes áreas de Lingua Portuguesa, de Matemática, de Ciências, e de Conhecimentos Históricos e Geográficos tenderão a impor suas próprias finalidades, mais cognitivas que atitudinais. Dentre os doze objetivos apresentados para o ensino fundamental, cinco referem-se, grosso modo, aos conteúdos das áreas curriculares, sendo que apenas um menciona explicitamente a Língua Portuguesa. Os demais sete objetivos, ou seja, dois terços deles, referem-se a objetivos ideológicos". (1996, p.63)

${ }^{9}$ Ver, a título de exemplo, as propostas curriculares elaboradas pela Secretaria de Estado da Educação de São Paulo, entre os anos 84 e 91, particularmente as de Física e de Sociologia.
} 
inquietação, conviver com o incerto e o imprevisivel, acolher e conviver com a diversidade [grifo nosso], valorizar a qualidade, a delicadeza, a sutileza, as formas lúdicas e alegóricas de conhecer o mundo e fazer do lazer, da sexualidade e da imaginação um exercício de liberdade responsável." (parágrafo I, artigo $3^{\circ}$ )

Esse nível de ensino voltado ao segmento jovem que hoje busca mais do que simplesmente conquistar um diploma, alguma perspectiva de vida para sair do impasse econômico, que exclui aceleradamente o aluno e sua família do mercado de trabalho e da possibilidade de acesso aos bens sociais e de consumo, deve ter como maior objetivo levá-lo ao questionamento, mais do que simplesmente à indagação (o que não se resume a discordâncias semânticas).

Deve levá-lo, ainda, a compreender a dinâmica das instituições sociais e políticas, não para suportar a inquietude, mas para usá-la em ações e atividades sociais capazes de modificar o estado de coisas vigente. Se os pilares que sustentam os mecanismos institucionais democráticos são vulneráveis, melhor será se esse jovem, mais do que apenas compreender o frágil dinamismo da democracia política brasileira, desenvolva atitudes e valores que a revigorem. Para isso, os antagonismos são necessários.

Os temas que vigoram atualmente nas propostas de currículo e que estão bem representados nas diretrizes em pauta - contemporâneos e referendados na dinâmica da transnacionalização da política, da economia e da cultura - mereceriam uma aproximação maior com os temas que hoje afetam a sociedade brasileira.

A compreensão do mundo do trabalho poderia ser construída, a partir de uma perspectiva crítica que abordasse sua organização contemporânea, bem como os diferentes determinantes da sua divisão técnica em nível internacional, observando-se, porém, as especificidades regionais e locais.

As relações de trabalho num mundo sem emprego mudam significativamente a importân- cia do discurso sobre a detenção de conhecimentos pragmáticos, voltados apenas para o atendimento das demandas de mercado. Faz-se necessário alargar essa compreensão para além do mundo formal do trabalho, destacando as potencialidades exigidas atualmente para inserção dos indivíduos nas indefinidas relações de mercado. Dessa forma, seria desejável que os alunos desenvolvessem competências críticas e criativas, para utilizá-las adequadamente em diferentes níveis de análise e avaliação sobre as graves conseqüências sociais marcadas pelas mudanças na organização da vida produtiva, bem como sobre as dificuldades de ingresso e permanência no mercado de trabalho formal.

Nesse sentido, seria de fundamental importância discutir o processo de constituição das relações sociais de produção em nível internacional e nacional - por mais arcaico que isso possa parecer - relacionando-o à história da industrialização e das lutas sindicais no país, possibilitando ao aluno a compreensão do processo de globalização da economia e da inserção desigual do país no mercado internacional.

Sublinhe-se que a construção de uma concepção de sociedade deveria permitir ao estudante do ensino médio estabelecer relações entre os diferentes elementos que a compõem e categorias que a definem, possibilitando a compreensão de seus mecanismos de funcionamento como uma totalidade capaz de expressar o que é diverso e parcial. Apenas a partir dessa concepção de sociedade e de mundo, seria possível levar o aluno a compreender a emergência de temas que hoje ocupam o cenário das manifestações sociais, tais como os movimentos étnicos, religiosos, raciais, sexuais, ecológicos, que exigem uma discussão sobre a diversidade cultural de uma perspectiva política, e não de ordem moral.

Poder-se-ia proporcionar, assim, a compreensão de que diferentes manifestações culturais são a legítima expressão de povos, nacionalidades, raças e etnias que atualmente buscam novas significações para suas identidades coletivas, a partir de mudanças políticas, econômicas e culturais 
que promoveram descontinuidades nos valores consagrados pelos princípios universais da democracia burguesa. A discussão sobre a formação de identidades sociais e pessoais, dessa forma, estaria relacionada ao princípio de respeito mútuo, que questiona o próprio elemento fundante da democracia burguesa ocidental, o princípio de igualdade que exclui aqueles que não são iguais:

"Governos, políticos e instituições, habituados a lidar com conflitos que tinham como eixo a busca de integração - de pobres, desempregados, marginalizados etc. - à sociedade mais ampla, estão hoje perplexos diante da pulverização progressiva da experiência social e da constatação cada vez mais recorrente, de que as especificidades culturais - sobretudo quando transformadas em direito à diferença - parecem fazer ruir a confiança na permanência da sociedade como entidade positiva, integradora e totalizadora." (Montero, 1998, p. 231)

A grande ausência, porém, como referência teórica nas diretrizes em pauta, são as questões relativas à reestruturação produtiva que promove no contexto da crise de governabilidade e legitimidade do Estado contemporâneo, uma retração de suas responsabilidades nos programas sociais; o desemprego estrutural; a fusão de corporações; a ampliação do poder das organizações e o aprofundamento das desigualdades econômicas e sociais.
Mesmo que os documentos oficiais tenham menosprezado a gravidade dos problemas econômicos que limitam profundamente as reais possibilidades da educação formal apontar saídas bem-sucedidas para a formação desses jovens, a realidade da rede escolar e seu cotidiano repleto de urgências promove a lucidez necessária nos profissionais da educação acostumados a dar novos significados às orientações legais e/ou oficiais.

Todo programa de governo expressa um mundo normatizador que sofre uma releitura por parte das escolas e dos profissionais da educação. O programa de reforma do ensino médio está sujeito à mesma dinâmica: entre o discurso governamental e as normas oficiais e/ou legais, haverá, necessariamente, um processo de ressig. nificação dessas orientações, originando um produto híbrido que se revelará apenas nas e pelas práticas dos educadores.

Entre os "objetivos espetaculares versus os resultados decepcionantes" - a síndrome que persiste no planejamento das políticas públicas no Brasil ${ }^{10}$ - é possível que as escolas de ensino médio construam seus próprios caminhos, para percorrer a intrincada relação com novos referenciais teóricos (Martins, 1997), contextualizando os temas culturais e políticos a partir da dinâmica da sociedade brasileira que, em última instância, tem sido profundamente afetada pelo redimensionamento da acumulação do capital.

${ }^{10}$ Sobre as características que configuram o planejamento de Estado no Brasil e a proposição de programas sociais, ver: Siqueira, 1990, p. 65-72.

\section{REFERÊNCIAS BIBLIOGRÁFICAS}

ALMEIDA, L. F. de. Entre o local e global: poder e política na atual fase de transnacionalização do capitalismo. In: DOW.

BOR, L.; IANNI, O.; REZENDE, E. A. (org.). Desafios da globalização. Petrópolis: Vozes, 1998. p. 175-86.

APEOESP. Revista de Educação. São Paulo: APEOESP, n. 10, abr., 1999.

ARGENTINA. Ministerio de Cultura y Educación. Contenidos básicos comunes para educación general básica. Argentina, 1994. AZANHA, J.M.P. Parecer sobre os Parâmetros Curriculares Nacionais. São Paulo: CEE/SP, 1996. (mimeo.)

BALL, S J. Cidadania global, consumo e política educacional. São Paulo: APEOESP, 1999. [trabalho apresentado na II Conferência Estadual de Educação.]

BARDIN, L. Análise de conteúdo. Lisboa: Edições 70, 1977.

BERNARDO, J. Economia dos conflitos sociais. São Paulo: Cortez, 1991.

BIRD. Relatório sobre o Desenvolvimento Mundial. Washington DC, 1995. 
BRASIL. Leis, Decretos etc. Decreto n. 2.208/97.

. Lei de Diretrizes e Bases da Educação Nacional n. 5.692/71.

. Leis, Decretos etc. Lei de Diretrizes e Bases da Educação Nacional n. 9.394/96.

. Parecer n. 15/98.

BRASIL. Ministério da Educação e Desporto. Conselho Nacional da Educação. Câmara de Educação Básica. Resolução n. 3 de 26/06/98 1998.

. Secretaria de Ensino Fundamental. Parâmetros Curriculares Nacionais para Educação Infantil. Brasília: MEC,

Secretaria de Ensino Fundamental. Parâmetros Curriculares Nacionais para 1ํㅡ a $4^{a}$ séries. Brasília: MEC, 1998.

BRASIL. Ministério de Educação e Desporto. Secretaria de Ensino Fundamental. Parâmetros Curriculares Nacionais para 5a a $8^{\text {a }}$ séries. Brasília: MEC, 1998.

. Secretaria de Educação Média e Tecnológica. Discutindo uma concepção curricular para o ensino médio: documento preliminar. Brasília, 1997.

Parâmetros Curriculares Nacionais para o Ensino Médio: Parte I — Bases Legais. Brasília, 1999.

CALAME, P. Transferências de tecnologia entre o norte e o sul: onde estão os mediadores? In: WITKOWSKI, N. et al. (org.). Ciência e tecnologia hoje. São Paulo: Ensaio, 1995, p. 433-37.

CARNOY, M.; CASTRO, C. de M. Documento de antecedentes para el Banco Interamericano de Desarrollo. Buenos Aires, 1996.

CHILE. Ministerio de Educación. Programa de mejoramiento de la calidad en esculeas básicas de sectores pobres: (programa de 900 escuelas). Santiago del Chile, 1991.

CUNHA, L. A. Os Parâmetros Curriculares para o Ensino Fundamental: convívio social e ética. Cadernos de Pesquisa. São Paulo: Cortez; FCC, n. 99, p. 60-73, nov. 1996.

DRAIBE, S. Brasil: o sistema de proteção social e suas transformações recentes. Campinas: Núcleo de Estudos em Políticas Públicas; UNICAMP; CEPAL, 1992 (mimeo.).

ESPANHA. Ministerio de Educación y Ciencia. Adaptaciones curriculares: primaria. Madrid, 1992.

. Área de conocimiento del medio. Madrid, 1992.

Transversales: educación para la igualdad de oportunidades de ambos os sexos. Madrid, 1992.

Transversales: educación para la salud - educación sexual. Madrid, 1992.

ESPANHA. Ministerio de Educación y Ciência; OCDE. Escuelas y calidad de la ensenãnza. Barcelona: Paidós, 1991.

FERRETTI, C. J. Formação profissional e reforma do ensino técnico no Brasil: anos 90. Educação e Sociedade, v.18, n. 59, ago, 1997.

FOUCAULT, M. História da sexualidade: a vontade de saber. Rio de Janeiro: Graal, 1977.

FRIGOTTO, G. Educação e formação técnico-profissional frente à globalização excludente e o desemprego estrutural. Revista de Educação. São Paulo: Apeoesp, n. 10, p. 4-17, abr. 1999.

GARRETÓN, M. A. A. Pontos fortes e fracos dos novos consensos sobre educação. Cadernos de Pesquisa. São Paulo: Cortez; FCC, n. 101, p. 113-28, jul.1997.

HARVEY, D. Condição pós-moderna. São Paulo: Loyola, 1996.

IANNI, O. A política mudou de lugar. In: DOWBOR, L.; IANNI, O. e REZENDE, P. E. A. (org.). Desafios da globalização. Petrópolis: Vozes, 1998. p. 17-27.

. A Sociedade global. Petrópolis: Vozes, 1995.

KAUFMANN, F. Metodologia das ciências sociais. Rio de Janeiro: Francisco Alves, 1977.

MARTINS, A M. A política do conhecimento: a identidade do saber e as reformas educativas. In: LINHARES, C. (org.). Políticas do conhecimento. Niterói: Intertexto, 1999, p. 71-101.

. Educação e diretrizes de mudança: possibilidades e limites do Estado. Estudos em Avaliação Educacional. São Paulo: FCC, n. 15, p. 7-55, jan./jun.1997. FE/USP.

. Mudança, resistência e educação: práticas profissionais e limites do Estado. São Paulo, 1996. Dissertação (Mestrado)

MIRANDA, M, G. O Novo paradigma de conhecimento e as políticas educativas na América Latina. Cadernos de Pesquisa. São Paulo: Cortez; FCC, n. 100, p. 37-49, mar.1997.

MONTERO, P. Reinventando as diferenças num mundo global. In: DOWBOR, L.; IANNI, O. e REZENDE, P. E. A. (org.). Desafios da globalização. Petrópolis: Vozes, 1998, p. 231-6.

ORGANIZACIÓN DE ESTADOS IBEROAMERICANOS/OEI PARA LA EDUCACIÓN, LA CIENCIA Y LA CULTURA. Governabilidade democrática e dos sistemas educacionais. Cadernos de Pesquisa. São Paulo: Cortez; FCC, n.100, p.121-49 mar.1997.

. II Reunion Subregional sobre la ensenãnza de la filosofia en el nivel medio. Mar del Plata, 1998.

ORTIZ, R. Mundialização, cultura e política. In: DOWBOR, L.; IANNI, O., REZENDE, P. E. A. (org.). Desafios da globali- 
zação. Petrópolis: Vozes, 1998. p. 270-5.

OTTONE, E. Repensar la educación secundaria. UNESCO; Ministerio de Educación: Santiago del Chile, 1996. (mimeo)

POPKEWITZ, T.S. Reforma educacional: uma política sociológica - poder e conhecimento em educação. Porto Alegre: Artes Médicas, 1997.

ROPÉ, F.; TANGUY, L. Saberes e Competências. Campinas: Papirus, 1998.

SANTOMÉ, J. T. Globalização e interdisciplinaridade: o currículo integrado. Porto Alegre: Artes Médicas, 1998.

SÃO PAULO (Estado). Secretaria da Educação. Coordenadoria de Estudos e Normas Pedagógicas. Proposta Curricular de Física. São Paulo.

SIQUEIRA, M. M. de. Eficácia da administração pública: imposição democrática. Revista de Administração de Empresas. São Paulo: Fundação Getúlio Vargas, p. 65-72, jan./mar. 1990.

TANGUY, L. O Deslocamento de noções: da qualificação à competência no mundo do trabalho e dos saberes à competência no mundo da formação. São Paulo: Pontifícia Universidade Católica. (Conferência gravada, em 3 de junho de 1996).

UNESCO. Relatório da reunião educação para o século XXI. Paris: UNESCO, 1994.

VEIGA-NETO, A J. Currículo, disciplina e interdisciplinaridade. Idéias, São Paulo, n. 26, 1995.

ZIBAS, D.; FRANCO, M.L.B. O Ensino médio no Brasil neste final do século: uma análise de indicadorés. São Paulo: FCC, 1999. (textos FCC, n. 18) 